Erazo, A., Guzman, G., and Espinoza, S. 2020. "Applying BIM Tools in IPD Project in Peru." In: Tommelein, I.D. and Daniel, E. (eds.). Proc. $28^{\text {th }}$ Annual Conference of the International Group for Lean Construction (IGLC28), Berkeley, California, USA, doi.org/10.24928/2020/0108, online at iglc.net.

\title{
APPLYING BIM TOOLS IN IPD PROJECT IN PERU
}

\author{
Andrews Erazo' ${ }^{1}$, Giankeving Guzman ${ }^{2}$, and Stefany Espinoza ${ }^{3}$
}

\begin{abstract}
Traditional project delivery models are characterized by poor interaction in the design and construction stages, the poor process of collaboration, communication, and integration between the customer, contractor, and subcontractors. Lean Construction and Building Information Modeling have been implemented with great success in different construction projects in Peru, however, projects with IPD collaborative contracts have little information about their application in Peru. The project application is a Fast Track type project for the Pan American Lima Games 2019. The paper aims to demonstrate that the use of BIM tools enhances collaboration and integration into an IPD project. It starts with a literary review of the topics and then describes the proposed BIM and IPD integration framework, and finally evaluates the metrics obtained.
\end{abstract}

\section{KEYWORDS}

Integrated Project Delivery (IPD), BIM, collaboration, ICE session.

\section{INTRODUCTION}

Peru was chosen in 2014 as the venue for the 2019 Pan-American games, however, the government delayed construction work to 2017 (RPP, 2017, January 17) where a government-government agreement was signed and a contract type was raised for this event. Thus the New Engineering Contract (NEC 3) and Integrated Project Delivery (IPD) model were adopted at some venues for the construction of principal venues. The adoption of IPD has had its application in different countries of the world such as Norway (Kalsaas et al. 2020), the USA (AIA 2010), and other countries.

Although the collaborative model has been available in the market for several years, cases in South America and especially in Peru are scarce (Medina, 2014). Kim et al. (2016) identified some benefits perceived of the application of IPD in Public Projects: reduced number of change orders, a win-win process, the continuity of preferences, and improved communication of stakeholders Infrastructure projects, as they become increasingly complex and challenging, take this complexity as a catalyst to move towards a collaborative approach. The high level of project complexity motivates an interruption in the dynamics of project teams for further integration (Gomez et al. 2018). Soler et al. (2017) argue that BIM interpreting it as Building Information Management has a positive impact on the Integrated Project Delivery Methodology, as the team can work

1 Graduate Student, National University of Engineering, Perú, aerazor@uni.edu, orcid.org/0000-00025639-573X

2 Research Assistant, Virtual Design and Construction Laboratory, Department of Civil Engineering, National University of Engineering, Perú, gguzmang@uni.pe, orcid.org/0000-0003-3008-7867

3 BIM Coordinator at COSAPI SA, sespinoza@cosapi.com.pe, orcid.org/0000-0002-6613-2589 
simultaneously on the same model. Working from the conception of a single virtual model is something that increases transparency and trust. Likewise, the growth and improvement of communication in the cloud makes the location of team members no longer a determining factor and allows a much faster relationship. The ability to maximize efforts between the members of a main contractor and subcontractors is diminished by the absence of tools and processes that can articulate collaboration. (Vicencio, 2015).

National BIM implementation studies agree that the full collaboration and integration of those involved is an enhancer to maximize results by having as an opportunity to improve the technology, process and policy trident.

The objectives of the present study are (1) to apply BIM techniques to improve the collaboration during construction and design stage of IPD Project, and (2) show the results of the implementation of BIM and IPD Integration.

\section{LITERATURE REVIEW}

\section{BIM}

The National Building Information Model Standard Project Committee (NBIM-US) holds a commonly accepted definition that is: Building Information Modeling (BIM) is a digital representation of the physical and functional characteristics of an installation. BIM is a shared knowledge resource for information about an installation that forms a reliable foundation for decisions throughout its lifecycle; defined as existing from the oldest conception to the demolition." In addition to posing as a basic premise of BIM that is the collaboration between different stakeholders to insert, extract, update or modify model information to support or reflect roles of this part. Ilozor and Kelly (2012) mention that the final stage of BIM implementations should be the IPD coinciding with several authors. Implementing BIM standards, processes, and tools involves additional effort at the planning stage to achieve improvements at the execution stage. In early incorporating the different actors that will be involved in the development of the project (Molina Pacheco et al. 2019).

\section{IPD}

The AIA (American Institute of Architects) updated the definition of IPD in 2014:

"It is a method of delivering a project that integrates people, systems, business structures, and practices, in a process that collaboratively puts the talents and visions of all participants to work to reduce losses and optimize efficiency through all phases of design, manufacturing, and construction. The Integrated Project Delivery Method contains at least all of the following:

1.- Continuous involvement of the owner, as well as key designers and builders.

2.- Business interests aligned through a shared risk/benefit system, including risk financial gains, that depend on the results of the project.

3.- Control of the joint project of the owner, as well as of the key designers and builders.

4.- Common contract between all parties or with mandatory and specific conditions of participation.

5.- Responsibility shared by the owner and key designers and builders." 
It is generated during the design, planning, and execution phases of a project as a formal collaboration. The multidisciplinary team shares risks and rewards, using appropriate technologies and processes. All of the above to optimize the metrics of cost, time and waste reduction. (Ilozor and Kelly, 2012) (Fischer, Reed, Khanzode, and Ashcraft, 2014) shows a simple framework for IPD where it describes the best way forward for the delivery of high-performance buildings. This framework addresses the integration of systems, processes, organization, and information for the creation of the highperformance building defined as usable, buildable, operable and sustainable (Figure 1).

Collaboration and integration are two pillars in IPD projects. The first is a data-driven activity, while integration is a knowledge-based activity. Integration is best given when initial collaboration focuses on exploring defining the problem, rather than discussing the solution proposed by someone else (Fakhimi et al. 2016).

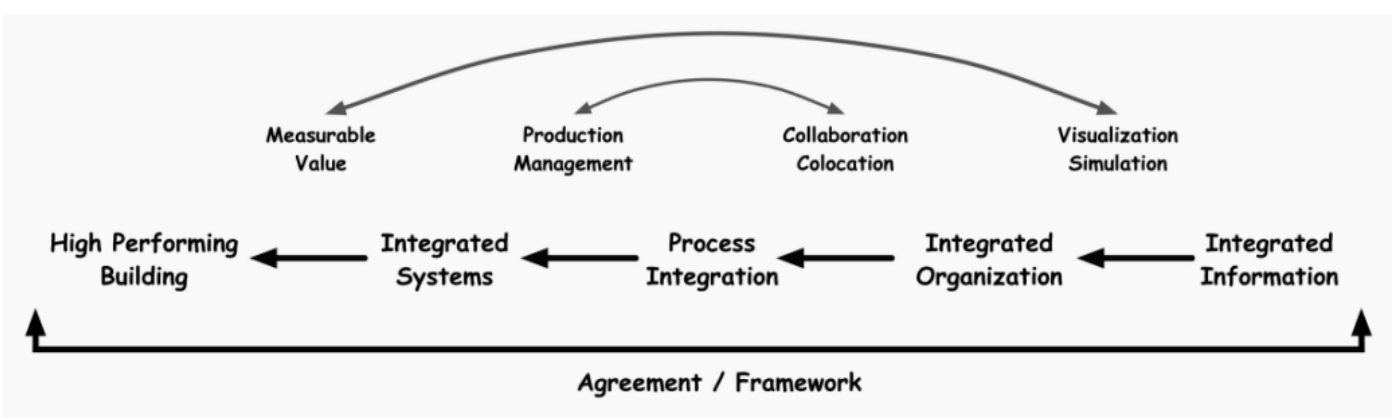

Figure 1: Simple Framework for Integrated Project Delivery (Fischer et al. 1994)

\section{METHODOLOGY}

The case focuses on an emblematic Peruvian project for the 2019 Lima Pan American Games. Because it had 18 months to complete the Design-Build, it was necessary to adopt new collaborative approaches such as IPD and propose flows based on BIM tools.

Workshops were held with the client, subcontractors, designers and the construction team in order to provide training in the use of the tools and processes being implemented. Feedback was also collected from those involved in order to make improvements in the processes. The main integration framework was as follows:

\section{CASE STUdY}

The case study is a fast track project that was born due to the need to have an adequate infrastructure for the Pan American Lima Games 2019, being for the first time in Peru where an IPD-type collaborative contract called NEC 3 (New Engineering Contract 3) is used. One of the principles of IPD is to use appropriate technology, the exchange of open and transparent data is essential to support IPD. A clear example of this is the BIM tools. This work will show the flows and processes using BIM tools that will ultimately help us measure the performance of BIM coordination throughout the design and construction stage. 

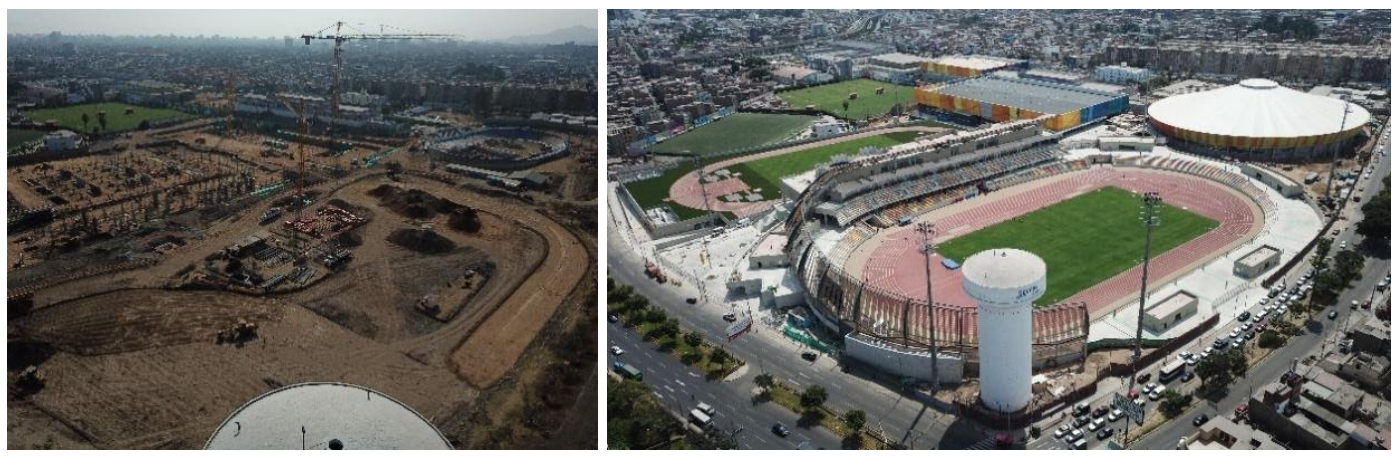

Figure 2: Photo taken with drone May 2018-Left, April 2019-Right

(Source: COSAPI S.A.)

\section{Proposed Process Of FLOW INTEGRATION BIM AND IPD}

One of the principles raised by the AIA (2014) is the use of good technology. Building Information Modeling (BIM) is an essential tool to achieve high levels of integration and collaboration within the IPD project. The flow frames a project within IPD principles, such as the early participation of stakeholders and the intensified planning. BIM tools are defined to support the processes in the design and construction phase, enhancing the integration of people (IPD), tools (BIM) and processes (Figure 3).

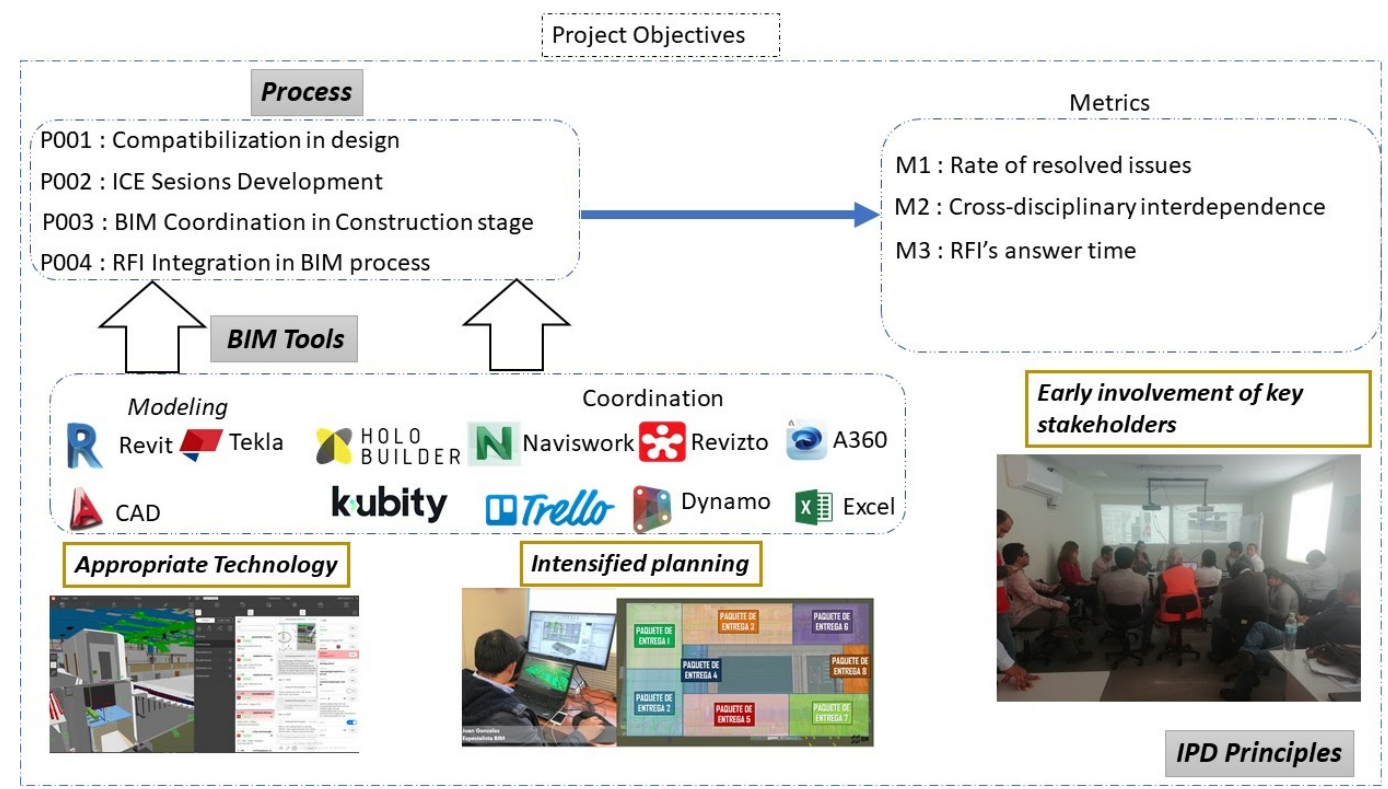

Figure 3: BIM and IPD Integration (Source: Own Elaboration)

This framework presents the methodology used in the case study and it is composed of the participation of stakeholders, processes, BIM tools and metrics.

The process shown in Figure 3 is integrated by the following components:

- P001-Compatibilization in design: Since the design was an iterative process, this flow was established with the sequence of compatibility among disciplines. 
- P002-ICE(Integrated Concurrent Engineering)Sessions Development: They are meetings where specialists make decisions for the resolution of critical issues.

- P003-BIM Coordination in Construction stage: In an attempt to have an exchange of information agreement, this flow of information was established.

- P004-RFI Integration in BIM process: Due to the issues are not a means of formal communication at the construction phase, they were integrated into the traditional RFI process.

Furthermore, different collaborative tools were used to facilitate access to the information of the BIM model by all stakeholders. It is necessary to mention that the "issues" (identified observations) are typical of the interaction language within the Revizto platform.

\section{RESULTS OF IMPLEMENTING PROCESS FLOW INTEGRATION BIM AND IPD}

\section{Tracking and Controlling Issues in Design Stage}

Figure 1 shows the growth of total issues at the design stage having a total of 360 issues for one of the sub-projects of the VIDENA also traceability of the issues in the resolved state, pending and progress.

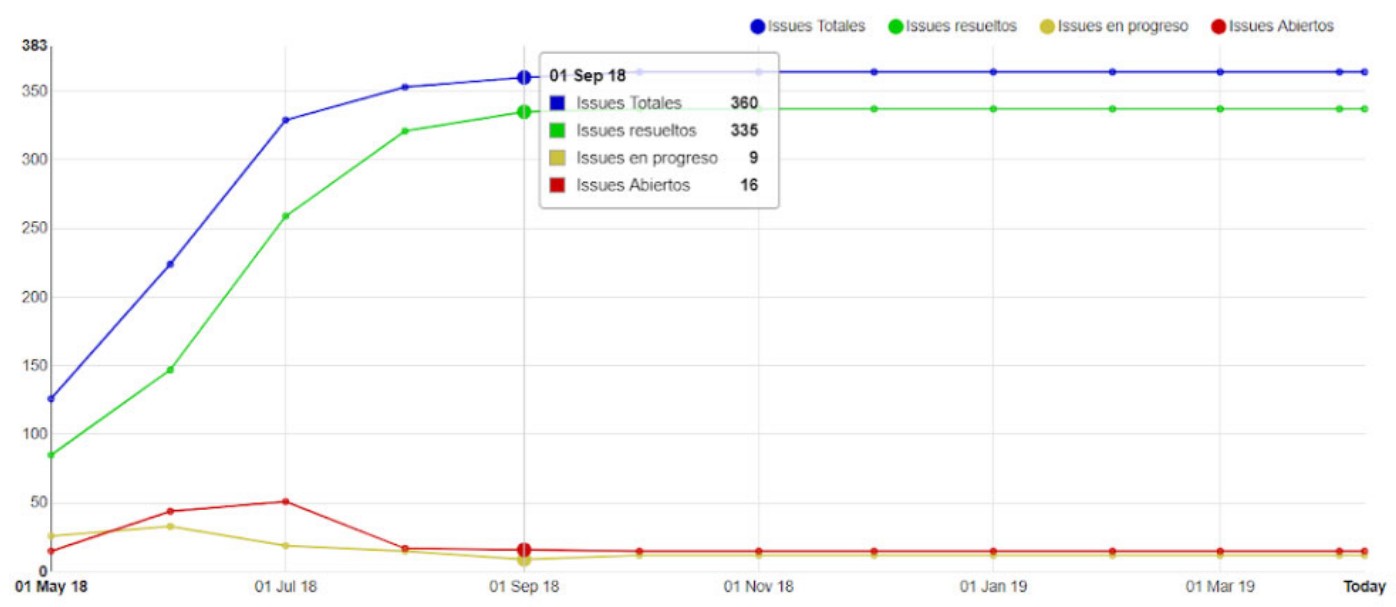

Figure 4: Tracking and controlling issues in design stage (Source: Revizto Web Platform)

\section{RATE OF RESOLVED ISSUES OVER TIME}

This metric shows the ratio of the number of resolved issues between the number of assigned issues for each discipline. An average ratio of $73.28 \%$ was determined, which indicates the collaboration of the design team and an increasing trend over time (see Figure 5). For example, if 10 issues were assigned to the architecture discipline, they solved 7 within the planned time frame. Also, this served to identify the disciplines that had low response rates and take corrective measures. 


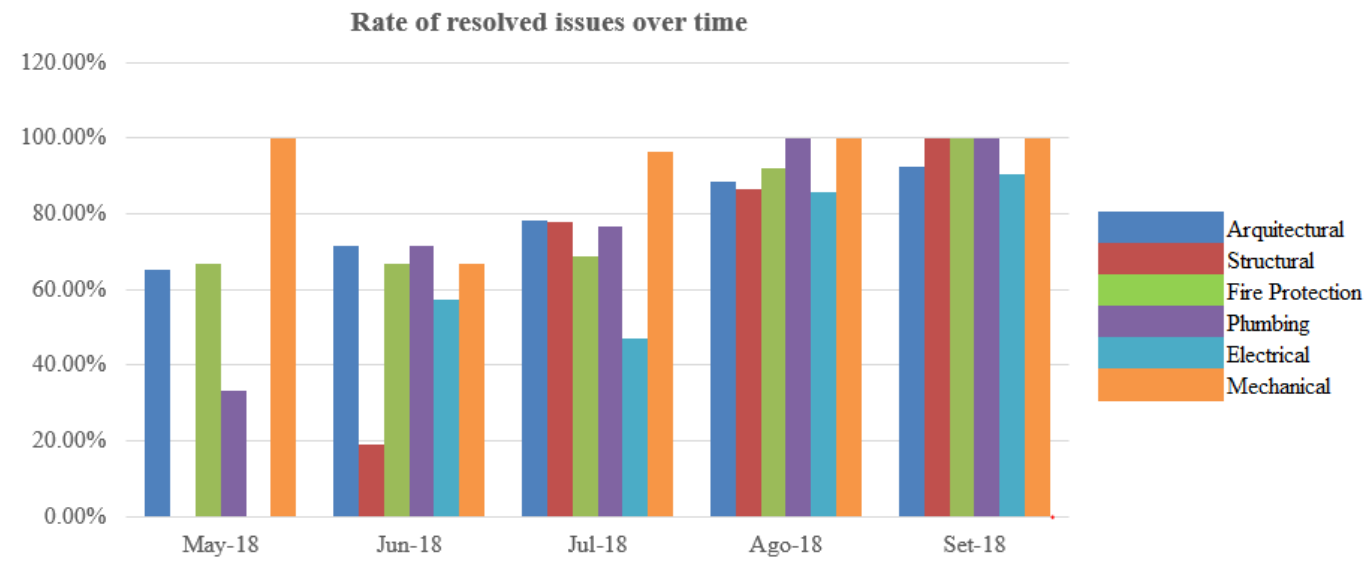

Figure 5: Ratio of resolved issues between assigned issues for each discipline (Source: Own Elaboration)

\section{CROSS-DISCIPLINARY INTERDEPENDENCE}

This metric shows the interdependence that exists between different disciplines. In other words, a problem or incompatibility in one specialty can have an impact on other specialties to a greater or lesser degree. HVAC is one of the specialties that has the greatest impact on Architecture, this is due to the limited height of the False Sky that restricts the installation of mechanical ducts.

\# of Interactions

\begin{tabular}{|c|c|c|c|c|c|c|c|c|c|}
\hline Specialty areas & 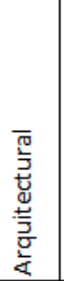 & 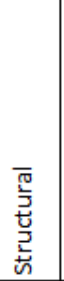 & 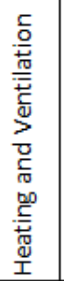 & $\frac{\text { 产 }}{\frac{0}{E}}$ & 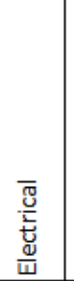 & $\begin{array}{l}E \\
\stackrel{U}{\mathbb{U}} \\
\stackrel{\mathbb{E}}{\leftarrow}\end{array}$ & 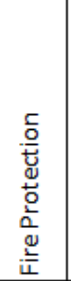 & 怘 & 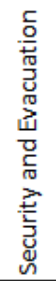 \\
\hline Arquitectural & 82 & 5 & 9 & 25 & 3 & 2 & 6 & & \\
\hline Structural & 15 & 46 & 1 & 3 & 3 & & 2 & & \\
\hline Heating and Ventilatior & 45 & 4 & 79 & 1 & 14 & & 1 & & \\
\hline Plumbing & 34 & 5 & 5 & 53 & & 1 & & & 1 \\
\hline Electrical & 16 & 1 & & & 31 & & & & 1 \\
\hline Telecom & 11 & & & & & 20 & 1 & & \\
\hline Fire Protection & 7 & 4 & 6 & & 7 & 4 & 58 & & \\
\hline Gas & 3 & 1 & & & & & & 6 & \\
\hline Security and Evacuatior & 2 & & & & & & 1 & & \\
\hline
\end{tabular}

Figure 6: Impact between specialties (Source: Own Elaboration)

\section{Classification OF REQUESTS FOR INFORMATION(RFI)}

To demonstrate the effectiveness of early collaboration supported by BIM tools, RFI emitted by subcontractors at the construction phase were classified. This classification is based on three categories based on previous studies (Alcantara, 2013 and Badin, 2018): 
The "Confirmation" category is when there is no certainty of some detail or information reflected in the plans and/or technical specifications, $70 \%$ of the RFI are within this category.

It is classified as "Improvement" when an added value is proposed to the scope of the project, $18 \%$ of the RFI are qualified as "Improvement".

The third category "Design Issues" refers to engineering incompatibility issues, 12\% qualify in this category.

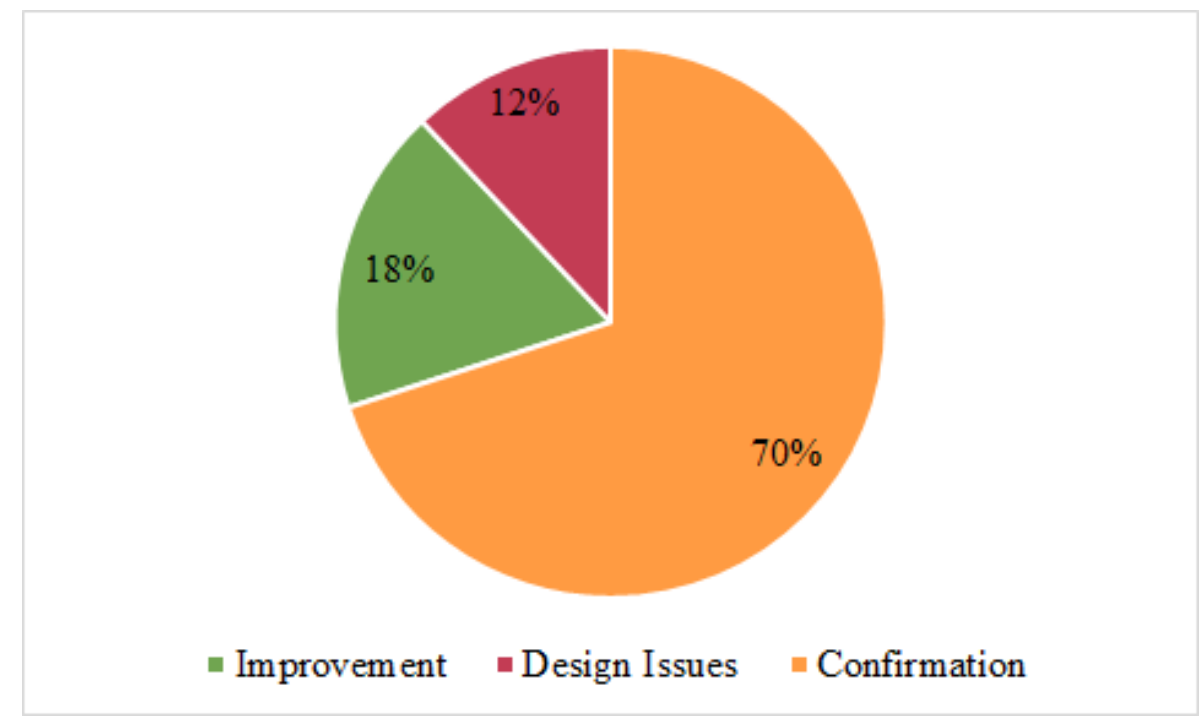

Figure 7: Classification of RFI at the Construction stage (Source: Own Elaboration)

Alcantara (2013) shows that in projects with similar conditions to the case study, about $60 \%$ of the RFI are due to design issues. Then, it is shown that working with BIM tools in early stages of the project reduces design problems, which finally has an impact on the construction phase.

\section{RFI ANSWER TIME}

In the construction phase, BIM flows were implemented to address the RFI of subcontractors. In this sense, a learning curve was experienced that can be seen in the following graph, where a response time of 40 days was reduced to one day. This had a positive impact on keeping a steady workflow. 


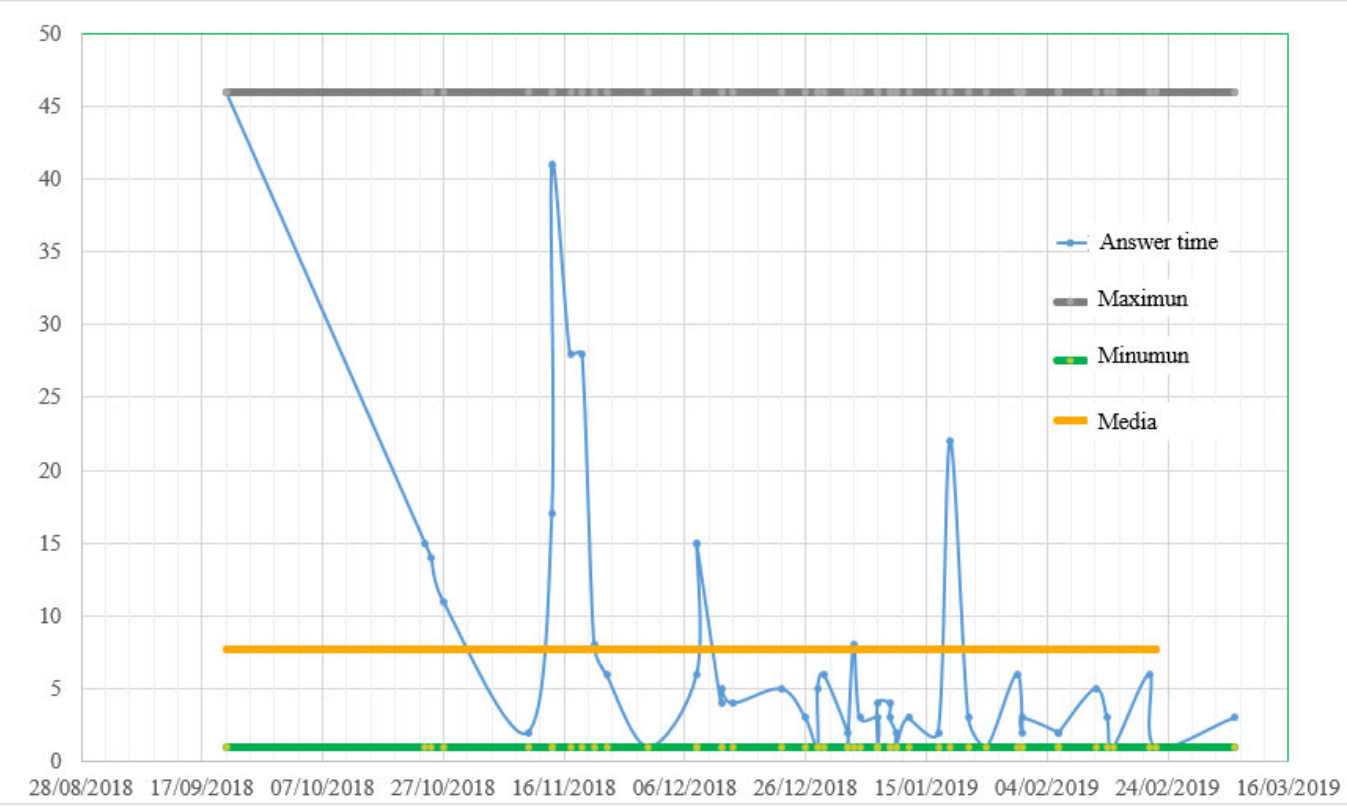

Figure 8: Trends in the answer time of RFIs

\section{CONCLUSIONS}

After the application of the BIM and IPD integration framework in the project design stage, it was possible to solve important problems of the project, improve efficiency during the construction stage and ensure value for the client, since the project could be delivered to the client in the term, cost and quality expected.

Through the ICE meetings, we were able to obtain better results in the RFI's response, since time was saved in their response. As you can see $70 \%$ are only confirmation, which reduced the response time. If traditional methods had been used and there had been no communication platform between all designers, this would have taken more time. The project has an average response time of the RFI's of 7 days, which is a pretty good average time. Viñas (2015); Guerrero, Isla, and Malpartida (2019); Bravo, Mendoza, and Ramírez (2019), perform the average RFIS time analysis, finding the response time between 21 to 20 days and mentioning that an ideal response time between 7 to 15 days. In the project, the average response time was 7 days, which shows that the integration and collaboration of specialists helped reduce the response time by $67 \%$ compared to a traditional management project. In addition, $18 \%$ of RFI's are value-added and only $12 \%$ were design problems. The effort and collaboration in the initial stage reduced the amount of RFI due to design problems. The proposed model allows that the participants in the design are very familiar with the coordination platform because it allows interacting very easily, An average ratio of $73.28 \%$ was determined, which indicates the collaboration of the design team and an increasing trend over time. For the design stage, there is a greater architectural implication (43\%), this because the design of the sports infrastructure for this type of events had not been done before in the country and there was little knowledge of norms and standards; The client also made changes during the project that were executed more quickly by integrating everything into a collaborative model. In the construction phase, there was a higher index in the Sanitary subcontractor, since the subcontractor was involved from the beginning with the workflow. 
One of the main points is that subcontractors could be integrated from the BIM model, so that they could generate their RFI's and warned of possible design deficiencies and became part of the model. An important learning was that the general contractor within its contract terms required subcontractors to have a person in charge of BIM to improve the flow of information in the project.

\section{REFERENCES}

AIA 2010. Integrated Project Delivery: Case Studies. Available at: $<$ https://www.ipda.ca/site/assets/files/1111/aia-2010-ipd-case-studies.pdf>

[Accessed 24 May 2020]

Alcantara, P. 2013. Metodología para minimizar las deficiencias de diseño basada en la construcción virtual usando tecnologías BIM. (in Spanish) [Methodology to minimize design deficiencies based on virtual construction using BIM technologies] BSc. National University of Engineering, Lima, Perú.

Bravo, A., Mendoza, J., and Ramirez, H. 2019. Application of Integrated Project Delivery and Virtual Design and Construction to reduce the impact of incompatibilities in the design stage in residential buildings. 17 th LACCEI International Multi-Conference for Engineering, Education, and Technology: "Industry, Innovation, and Infrastructure for Sustainable Cities and Communities", Jamaica.

Fakhimi, A., Majrouhi, J., and Azhar, S. 2016. How can Lean, IPD, and BIM work together? 33rd Int. Symp. on Automation and Robotic in Construction (ISARC 2016). Kashan, Iran.

Fischer, M., Reed, D., Khanzode, A., and Ashcraft, H. 2014. A simple framework for Integrated Project Delivery. IGLC-22, (p. 1319-1330). Oslo, Norway.

Gomez, S., Ballard, G., Naderpajouh, N., and Ruiz, S. 2018. Integrated Project Delivery for infraestructure projects in Peru. 26 th Annual Conference of the International Group for Lean Construction,(p. 452-462). Chennai, India.

Guerrero J., Isla, J., and Malpartida, Z. 2019. Gestión de proyectos en la fase de diseño de tipo edificación: "Residencial CANVAS" ubicado en la ciudad de Lima. (in Spanish) [Project management in the design phase of building type: "Residential CANVAS" located in the city of Lima.] Master of Construction Direction, Peruvian University of Applied Sciences, Lima, Perú.

Ilozor, B., and Kelly, D. 2012. Building Information Modeling and Integrated Project Delivery in the Commercial Construction Industry: A conceptual study. Journal of Engineering, Project, and Production Management, (p. 23-36). Michigan, USA.

Kalsaas, B. T., Nwajei, U.O.K., and Bydall, C. 2020. "A critical perspective on Integrated Project Delivery (IPD) applied in a Norwegian public hospital project." In MATEC Web of Conferences (Vol. 312, p. 07001). EDP Sciences.

Kim, Y., Rezqallah, K., Lee, H. W., and Angeley, J. 2016, “'Integrated Project Delivery in Public Projects: Limitations and Opportunity" In: 24th Annual Conference of the International Group for Lean Construction. Boston, USA.

Medina, A. 2014. "Learning through Failure - the Challenge of Lean Project Delivery from the Contractor's Perspective in Peru" In: Kalsaas, B. T., Koskela, L. and Saurin, T. A., 22nd Annual Conference of the International Group for Lean Construction. Oslo, Norway, pp 1425-1433

Molina Pacheco, V., Fernando Herrera, R., Muñoz La Rivera, F., and Cazaux Miranda, G. 2019. Technical-Economical Evaluation of BIM Modeling and Coordination in 
Medium size building projects. Journal of BIM and Construction Management. Valparaiso, Chile.

Soler, M., Armiñana, E., and Alvarez-Perez, M.-A. 2017. "Los métodos colaborativos (Integrated Project Delivery), una metodología Lean Construction que mejora el Proceso Constructivo." (in Spanish) [Collaborative Methods (Integrated Project Delivery) a Lean Construction Methodology that enhances the construction process]. In: $2^{\text {nd }}$ CITE Congress, Madrid.

Vicencio, G. 2015. Desarrollo del sistema último planificador usando tecnología BIM$4 D$ en proyectos de construcción. (in Spanish) [Development of the Last Planner system using BIM-4D on construction projects.] BSc, National University of Engineering, Lima, Perú.

Viñas V. 2015. BIM, para asegurar el costo contractual de obra y su implementación en un proyecto multifamiliar. (in Spanish) [BIM, to ensure the contractual cost of the work and its implementation in a multi-family project.] Peruvian University of Applied Sciences, Lima, Perú. 
Andrews Erazo, Giankeving Guzman, and Stefany Espinoza

This page was intentionally left blank. 
Applying BIM Tools in IPD Project in Peru

This page was intentionally left blank. 